\title{
Voice Handicap and Health-Related Quality of Life in Laryngectomees: Assessments with the Use of VHI and EORTC Questionnaires
}

\author{
Elisabet Lundström ${ }^{\mathrm{a}}$ Britta Hammarberg ${ }^{\mathrm{a}}$ Eva Munck-Wikland ${ }^{\mathrm{b}}$

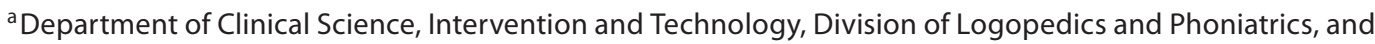 \\ ${ }^{b}$ Department of Clinical Neuroscience, Division of Otorhinolaryngology and Hearing, Karolinska Institute, \\ Stockholm, Sweden
}

\section{Key Words}

Laryngectomy $\cdot$ Quality of life $\cdot$ Voice Handicap Index

\begin{abstract}
Aims: To investigate the Voice Handicap Index (VHI), the health-related quality of life (HRQL), and the correlations between VHI and HRQL in laryngectomees. Methods: Fortythree laryngectomized persons participated (mean age 68;6 years, time since laryngectomy between $0 ; 6$ and 12 years). Evaluation of voice handicap was done with the VHI. HRQL was evaluated with questionnaires from the European Organization for Research and Treatment of Cancer, EORTC QLQ-C30 and EORTC QLQ-H\&N35. Results: VHI for the whole group demonstrated a moderate voice handicap, with a mean score of $48 / 120$. The functional scales of EORTC QLQC30 resulted in scores on the same level as the normal population with the exception of a lower global quality of life scale (Global QOL). EORTC QLQ-H\&N35 revealed problems with smell and taste, speech, coughing, xerostomia, and sexuality. VHI correlated significantly with the Global QOL, the functional scales, dyspnea, pain, nausea and financial difficulties (EORTC QLQ-C30). Significant correlations were also found between VHI and speech problems, social contact,
\end{abstract}

pain from the head and neck area, sense problems, sexuality and social eating (EORTC QLQ-H\&N35). Conclusion: The EORTC questionnaires in combination with the VHI questionnaire seem to capture most of the problems following laryngectomy, including voice problems.

Copyright $\odot 2009$ S. Karger AG, Basel

\section{Introduction}

Laryngectomized patients are sometimes viewed as a relatively homogeneous group among head and neck cancer patients because their physical post-surgery problems are relatively alike. After a laryngectomy all patients suffer from problems due to changed airway, loss of normal voice, restricted body strength and reduced senses of smell and taste. However, during the past 25 years, efforts have been made to improve rehabilitation for the laryngectomees. The voice prostheses $[1,2]$ have radically reduced the time for laryngectomees to reestablish a functional voice. Respiratory problems have also decreased due to the introduction of tracheostoma protections with heat and moisture exchanger. The use of a heat and moisture exchanger has led to fewer problems with cough and

\section{KARGER}

Fax +4161306 1234

E-Mail karger@karger.ch

www.karger.com
(C) 2009 S. Karger AG, Basel

1021-7762/09/0612-0083\$26.00/0

Accessible online at:

www.karger.com/fpl
Elisabet Lundström

Karolinska Institute, Division of Logopedics and Phoniatrics

Karolinska University Hospital, Huddinge

SE-141 86 Stockholm (Sweden)

Tel. +4685177 4290, Fax +4685177 2518, E-Mail elisabet.lundstrom@karolinska.se 
bronchial infections [3] and can also improve voice function, especially for laryngectomees who use tracheoesophageal (TE) speech [4].

The evaluation of voice rehabilitation may include the patient's own voice perception and how his/her voice functions in different situations. The Voice Handicap In$\operatorname{dex}(\mathrm{VHI})$ is a validated instrument, originally developed as an instrument for the quantification of the psychosocial consequences of voice disorders [5]. The VHI has been translated and validated in several languages. In a study by Verdonck-de Leeuw et al. [6], the results showed that the translated and validated versions of VHI from eight European countries, among them Sweden, were equivalent to the original American version, i.e. VHI results from these countries can be compared. In the development of the VHI, laryngectomees constituted a substantial part (26\%) of the group of 65 patients who completed the preliminary version. Up until now only a few studies have reported VHI data for laryngectomees [711]. Studies by Stewart et al. [7] and Schuster et al. [10] compared VHI data with aspects of health-related quality of life (HRQL) in laryngectomees. In these two studies, HRQL was measured by use of the Short Form 36item Health Survey (SF-36) [12], a questionnaire suitable for different types of patients and problems, but not specifically aimed at cancer patients. The SF-36 has also been used in other studies of laryngectomees $[13,14]$. The results from the study by Stewart et al. [7] showed that a group of 56 laryngectomees graded their voice handicap higher than a group of 24 patients treated with radiotherapy only, although there was a considerable overlap between the groups. Several studies have focused on the long-term quality of life in head and neck cancer patients [15-20], using questionnaires developed by the European Organization for Research and Treatment of Cancer (EORTC). In addition to a basic questionnaire, EORTC QLQ-C30 [21], the EORTC has also developed a specific module for head and neck cancer, EORTC QLQ-H\&N35 [22]. Both questionnaires from the EORTC are validated $[22,23]$ and have been translated into many languages. The EORTC Quality of Life Group grants permission to employ the questionnaires and supplies the user with the currently available translation asked for, as well as the standard algorithms for scoring the EORTC questionnaires. In previous prospective Scandinavian studies of head and neck cancer patients [16-19], radiotherapy was given as the first-choice treatment for patients with laryngeal cancer, and at follow-up only a few of them had been treated with surgery, i.e. laryngectomy. Therefore, from these studies, data about HRQL for laryngectomees are sparse. In a Brazilian study [20] of 14 totally and 16 partially laryngectomized patients, EORTC QLQ-C30 and EORTC QLQ-H\&N35 were used to investigate the patients' quality of life after surgery. Although the median global quality of life score was identical for the two patient groups, speech problems were reported more frequently by the totally laryngectomized than by the partially laryngectomized. A study of 79 laryngectomees in the Netherlands, also using the EORTC questionnaires, showed a high quality of life score for the laryngectomees. The results also revealed that the EORTC questionnaires did not capture all of the difficulties for a laryngectomee, especially regarding respiration and voice [24].

For many laryngectomees, voice rehabilitation helps restore a functional voice and intelligible speech, although some of them may need additional communication aids or use an electrolarynx. The changed voice function, as well as other physical changes after laryngectomy, remains not only for a short postoperative period, but to some extent throughout life. The purpose of the present study was to investigate the voice handicap and HRQL in a group of laryngectomees by means of the VHI and a cancer-specific questionnaire (EORTC), and to compare the self-reported voice problems with other functions and symptoms.

\section{Methods}

Participants

A letter of information about the study was sent to a group of 54 consecutive laryngectomized patients who had undergone surgery at the Karolinska University Hospital from 1988 to 2005. Eleven patients declined participation in the study, 2 of them due to other illnesses, 3 due to geographically long distance, and another 6 did not want to participate in a research study. This resulted in a final sample of 43 totally laryngectomized patients (response rate $80 \%$ ).

In table 1 , patient characteristics are reported. There were 40 men and 3 women, with a mean age of 68 years (range 48-84) and a mean follow-up of 4.5 years (range 6 months to 12 years). Thirty-two patients received preoperative radiotherapy, 8 were given postoperative radiotherapy, while 3 patients did not receive any radiotherapy. Thirty-eight patients used TE speech as their main way of communication. Of the 5 patients using electrolarynx for communication, 2 had undergone more extensive surgery including free flap reconstruction. The remaining 3 had a severely restricted ability to use an esophageal voice source due to constrictions in the pharyngoesophageal area. All patients were daily users of a heat and moisture exchanger. At the time of the investigation 6 patients were working full- or part-time. Five patients were still on sick leave, although 2 of them had begun their working rehabilitation program. Thirty-two of the patients were retired, and 4 of these had received early retirement due to illness. 


\section{Questionnaires}

The 43 patients were asked to fill in three questionnaires at one visit to the Department of Speech-Language Pathology. The questionnaires assessed their voice handicap and their HRQL. The majority of the patients completed the questionnaires without assistance, but one of the authors (E.L.) was available for explanations of the questions, if needed. The three questionnaires used in the study were:

Voice Handicap Index. The VHI is a patient report instrument consisting of 30 statements on voice-related aspects $[5,25]$. The patient is asked to read each statement and indicate how frequently that statement applies to his/her individual situation, ranging from 0 (= never) to 4 (= always). The statements represent three subgroups, reflecting functional, physical and emotional aspects of the voice handicap. Within each subgroup, the index is $0-40$, with 0 meaning 'no voice handicap' and 40 meaning 'maximal voice handicap'. Thus, the total VHI is $0-120$. The interpretation of the mean total VHI is that a score between 0 and 30 reflects a minimal/mild VHI, a score between 31 and 60 reflects a moderate $\mathrm{VHI}$, and a severe voice handicap is reflected by a total VHI score from 61 to 120 (maximum) [26].

EORTC QLQ-C30. This questionnaire comprises multi-item functional and symptom scales, a global quality of life scale, and single-item questions, making a total of 30 questions [21]. There are eight scales, five scales for functions: physical, emotional, role, cognitive, and social, and three scales for symptoms: fatigue, nausea/vomiting, and pain. The six single-item questions concerns dyspnea, insomnia, loss of appetite, constipation, diarrhea, and financial difficulties. The patient is asked to answer questions about his/her health status during the past week. For all questions, apart from the global quality of life scale, the response is given on a four-level score with ' 1 ' indicating 'not at all' and ' 4 ' indicating 'a lot'. The responses to the two questions about global quality of health and life are given on a seven-level score, with ' 1 ' indicating 'very bad' and '7' indicating 'excellent'.

EORTC QLQ-H\&N35. This questionnaire consists of 35 questions, developed for patients diagnosed with a tumor in the head and neck area [22]. Similar to the QLQ-C30, this questionnaire uses a 1-week frame for the answers. Seven symptom scales are included, concerning problems with pain from the head and neck area, swallowing, senses (smell and taste), speech, social eating, social contact, and sexuality. There are also six single-item questions about problems with teeth, opening mouth, dry mouth, sticky saliva, coughing, and feeling of illness. The symptom scales and the single-item questions are scored from 1 to 4 with ' 1 ' indicating 'not at all' and '4' indicating 'a lot'. The questionnaire also includes five single-item questions about use of analgesics, nutritional supplements, feeding tube, and experience of weight loss or weight gain during the past week. These questions are to be answered with yes/no, and since most of the patients answered 'no', we have chosen not to present the results from these questions.

\section{Statistical Analyses}

For the VHI questionnaire, total VHI score and scores of the three subscales, respectively, were calculated as recommended in the original study by Jacobson et al. [5].

For the EORTC QLQ-C30 and EORTC QLQ-H\&N35, a linear transformation to a ' $0-100$ ' scale was carried out as suggested in the EORTC QLQ scoring manual [27]. A high score for the global quality of life scale, as well as for the other five functional scales
Table 1. Patient characteristics $(n=43)$

$\begin{array}{lc}\text { Gender } & \\ \text { Male } & 30 \\ \text { Female } & 3 \\ \text { Age at the time of the study, years } & \\ \text { Mean } \pm \text { SD } & 68 ; 3 \pm 9 ; 8 \\ \text { Median } & 68 ; 9 \\ \quad \text { Range } & 48-84 \\ \text { Years after laryngectomy } & \\ \quad \text { Mean } \pm \text { SD } & 4 ; 6 \pm 3 ; 6 \\ \quad \text { Median } & 4 ; 0 \\ \quad \text { Range } & 0 ; 6-12 \\ \text { Radiotherapy } & \\ \quad \text { Preoperative } & 32 \\ \quad \text { Postoperative } & 8 \\ \quad \text { None } & 3 \\ \text { Vocal rehabilitation } & \\ \text { TE voice } & 38 \\ \quad \text { Electrolarynx } & 5 \\ \text { Employment } & \\ \quad \text { Employed } & 6 \\ \quad \text { On sick leave } & 5 \\ \text { Early retirement due to illness } & 4 \\ \text { Retirement } & 28\end{array}$

represents a high HRQL. For the symptom scales and the singleitem questions a high score represents a high level of problems.

The statistical analyses include descriptive analyses of each questionnaire. For these analyses we used means and standard deviations (SD). For comparisons between speaker groups, we used Fisher's nonparametric permutation test. For comparisons between subgroups, in exploring any differences in VHI and HRQL depending on age $(<60,60-69, \geq 70$ years $)$ or on the length of the postoperative period $(<1,1-4, \geq 5$ years postoperatively), we used the Kruskal-Wallis test. For correlation analysis, Pitman's nonparametric test was used. Level of significance was set to $\mathrm{p}=0.05$ for all tests.

\section{Ethical Considerations}

All participants gave their informed consent. The local ethics committee at Karolinska University Hospital approved the study (Dnr 03/465).

\section{Results}

Comparisons (Fisher's test) between quality of life score and VHI scores for the TE speakers $(n=38)$ and the electrolarynx speakers $(n=5)$ showed no significant difference between the speaker groups. Therefore, results for the two speaker groups were compounded. As regards gender, results of the VHI and the EORTC questionnaires 


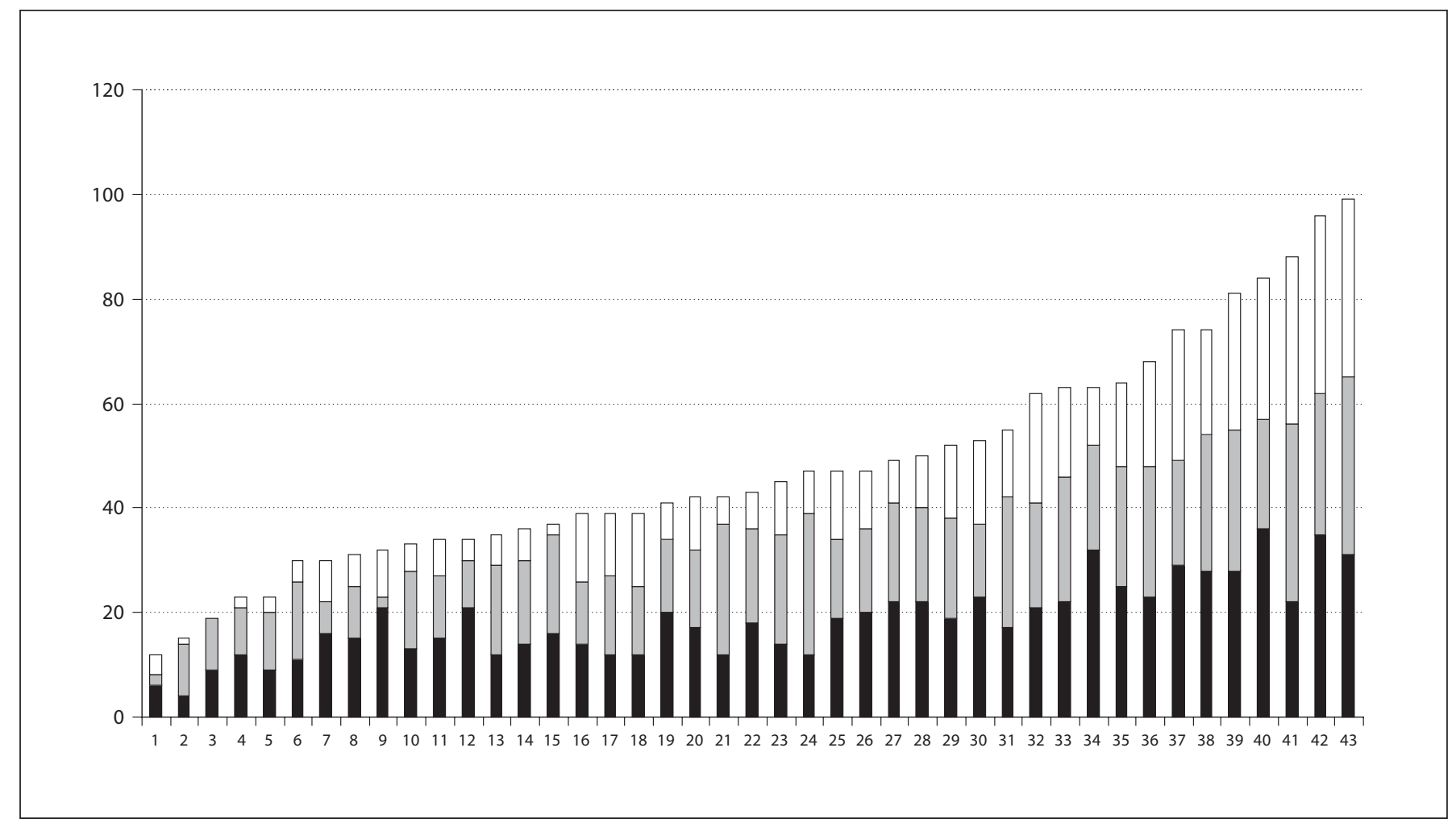

Fig. 1. VHI scores for each individual in the group of 43 patients. VHI scores are on the $y$-axis (a higher score indicates a more severe voice handicap). On the $\mathrm{x}$-axis the patients' scores are shown from the lowest to the highest VHI score. Seven patients rated their VHI with values below 30 (low/minimal problems). The larger part of the group, 24 patients (patients 8-31), rated their VHI with values between 31 and 60 (moderate problems). Twelve patients (patients 32-43) rated their VHI with values from 61 and up to 99 (severe problems). The black parts of the columns indicate the functional subscale, the gray parts the physical subscale and the white parts the emotional subscale. As can be seen in the figure, the higher the VHI score, the more equal was the distribution among the three subscales. from the 3 women did not differ from the results of the men $(n=40)$.

Results are mainly reported for the entire group of 43 patients, but VHI results are also given for subgroups as regards age and length of postoperative period.

\section{Voice Handicap Index}

Mean total VHI score for the patients in this study was $48.0 \pm$ (SD) 21.2, range 12-99. In figure 1, the VHI scores are shown for each patient and plotted from the lowest to the highest. The VHI severity degree $[5,26]$ showed that 24 patients (56\%) perceived their voice handicap as moderate. Twelve patients (28\%) perceived a severe voice handicap, and 7 patients (16\%) graded their voice handicap as minimal/mild. The division of the total VHI score into the three subscales showed that the functional and physical subscales were scored higher compared to the emotional subscale: functional $17.3 \pm$ (SD) 7.4, physical $18.6 \pm(\mathrm{SD}) 7.5$, and emotional $12.1 \pm$ (SD) 8.9, although these differences were not statistically significant.

The patients who were younger than 60 years at the time of the investigation received about ten points higher mean VHI scores (total VHI 57.9, $\mathrm{n}=9$ ) compared to the group age 60-69 (total VHI 48.8, $\mathrm{n}=16$ ) and to the group older than 70 (total VHI 42.4, $\mathrm{n}=18$ ). The length of the postoperative period also seemed to affect VHI scores. The mean score for the 9 patients who had lived as laryngectomees for less than a year was 60.9. Patients who had undergone surgery 1-5 years before the assessment had a mean score of $47.8(\mathrm{n}=17)$, and patients who had had a postoperative period of more than 5 years received a mean of $41.6(n=17)$. These differences between subgroups were not statistically significant. 
The two statements with the highest VHI score in the patient group of 43 reflected difficulties in making oneself heard and understood in a noisy room and difficulties to call out loudly. Fifty-three percent of the patient group chose the response 'almost always' or 'always' for the statement 'People have difficulty understanding me in a noisy room'.

\section{Health-Related Quality of Life}

The results from the EORTC questionnaires are shown in table 2 as means and standard deviations from the mean. Mean values for the functional scales in the EORTC QLQ-C30 ranged between 74.8 and 82.6, with a higher score reflecting better function. The global quality of life scale (Global QOL) scored lower than the other functional scales, with a mean of 66.8 for the whole subject group.

The symptom scales and items in the EORTC QLQC30 received relatively low scores, i.e. the subjects did not have large problems in these areas. Problems with fatigue, dyspnea, and insomnia resulted in scores higher than 20 , with the highest score for dyspnea (36.4). Financial difficulties (20.9) were mainly reported by the younger participants.

In the EORTC QLQ-H\&N35, the scale 'sense problems' received the highest score, 65.1/100. The scale summarizes problems with both smell and taste. Looking at the separate question about smell, $88 \%$ of the patients answered 'quite a bit' or 'very much' when asked about having problems with their sense of smell. Regarding the question about problems with taste, $49 \%$ of the patients answered 'quite a bit' or 'very much'. Speech problems and problems with teeth, sticky saliva, dry mouth, coughing, and sexuality received scores between 30 and 40 . The mean score for swallowing problems was 24.4. This scale is a summary of three questions about difficulties with liquids, pureed and solid food. Sixteen patients (37\%) reported difficulties with solid food. Nine of these $16 \mathrm{pa}-$ tients also reported difficulties eating together with others and enjoying their meals.

\section{Correlations between the Global QOL Scale and the}

Other Scales/Items of the EORTC Questionnaires

Table 3 presents correlations, and the level of significance, between the Global QOL and all other scales and items of EORTC QLQ-C30 and EORTC QLQ-H\&N35 for the entire subject group. The Global QOL correlated significantly with every other functional scale in the EORTC QLQ-C30. For all scales but the cognitive scale $(r=0.34, p<0.05)$, the significance level was $p<0.001$
Table 2. Results obtained from EORTC questionnaires $(n=43)$

\begin{tabular}{|c|c|}
\hline EORTC scales/items & Mean \pm SD \\
\hline \multicolumn{2}{|l|}{ QLQ-C30 } \\
\hline \multicolumn{2}{|l|}{ Functional scales } \\
\hline Physical function & $79.4 \pm 16.6$ \\
\hline Role function & $74.8 \pm 25.0$ \\
\hline Emotional function & $79.3 \pm 26.1$ \\
\hline Cognitive function & $82.6 \pm 22.4$ \\
\hline Social function & $79.8 \pm 25.3$ \\
\hline Global QOL & $66.8 \pm 20.9$ \\
\hline \multicolumn{2}{|l|}{ Symptom scales/item } \\
\hline Fatigue & $28.1 \pm 22.4$ \\
\hline Nausea and vomiting & $2.3 \pm 6.9$ \\
\hline Pain & $13.6 \pm 24.2$ \\
\hline Dyspnea & $36.4 \pm 28.0$ \\
\hline Insomnia & $23.3 \pm 34.5$ \\
\hline Appetite loss & $17.0 \pm 29.4$ \\
\hline Constipation & $13.2 \pm 20.7$ \\
\hline Diarrhea & $6.2 \pm 15.0$ \\
\hline Financial difficulties & $20.9 \pm 30.0$ \\
\hline \multicolumn{2}{|l|}{ QLQ-H\&N35 } \\
\hline \multicolumn{2}{|l|}{ Symptom scales/item } \\
\hline Pain & $9.5 \pm 17.6$ \\
\hline Swallowing & $24.4 \pm 22.8$ \\
\hline Sense problems & $65.1 \pm 24.3$ \\
\hline Speech problems & $30.7 \pm 23.4$ \\
\hline Social eating & $21.2 \pm 23.4$ \\
\hline Social contact & $11.0 \pm 16.9$ \\
\hline Sexuality & $38.1 \pm 38.7$ \\
\hline Teeth & $37.3 \pm 40.5$ \\
\hline Opening mouth & $11.7 \pm 24.0$ \\
\hline Dry mouth & $33.3 \pm 34.9$ \\
\hline Sticky saliva & $37.3 \pm 34.7$ \\
\hline Coughing & $31.0 \pm 34.4$ \\
\hline Feeling ill & $17.0 \pm 29.4$ \\
\hline \multicolumn{2}{|c|}{$\begin{array}{l}\text { Results are presented as means } \pm \text { SD. A higher score in a func- } \\
\text { tional scale and for the Global QOL scale reflects a higher quality } \\
\text { of life. A higher score in a symptom scale/item reflects a higher } \\
\text { level of symptoms, i.e. a higher degree of problems. }\end{array}$} \\
\hline
\end{tabular}

$(\mathrm{r}=0.49-0.68)$. Significant correlations were also found between Global QOL and fatigue, appetite loss, insomnia, and pain. Several scales and items of the EORTC QLQ-H\&N35 also correlated significantly with Global QOL, i.e. swallowing, sense problems, social eating, social contact, sexuality, dry mouth, sticky saliva, and feeling of illness. The speech scale and many of the aspects which may affect speech and respiration, i.e. teeth, mouth opening/trismus, dyspnea, and coughing, did not correlate significantly with Global QOL. 
Table 3. Correlations (Pitman's nonparametric permutation test) between the Global QOL scale and all other scales/items in the EORTC QLQ-C30 and EORTC QLQ-H\&N35

\begin{tabular}{|c|c|c|}
\hline EORTC scales/items & Corr. & $\mathrm{p}$ \\
\hline \multicolumn{3}{|l|}{ QLQ-C30 } \\
\hline \multicolumn{3}{|l|}{ Functional scales } \\
\hline Physical function & $0.55^{* * *}$ & \\
\hline Role function & $0.68^{* * *}$ & \\
\hline Emotional function & $0.58^{* * *}$ & \\
\hline Cognitive function & $0.34^{*}$ & \\
\hline Social function & $0.49^{* * *}$ & \\
\hline \multicolumn{3}{|l|}{ Symptom scales/item } \\
\hline Fatigue & $-0.58^{* * *}$ & \\
\hline Nausea and vomiting & -0.30 & NS \\
\hline Pain & $-0.33^{*}$ & \\
\hline Dyspnea & -0.25 & NS \\
\hline Insomnia & $-0.47^{* *}$ & \\
\hline Appetite loss & $-0.62^{* * *}$ & \\
\hline Constipation & $-0.36^{*}$ & \\
\hline Diarrhea & 0.18 & NS \\
\hline Financial difficulties & -0.29 & NS \\
\hline \multicolumn{3}{|l|}{ QLQ-H\&N35 } \\
\hline \multicolumn{3}{|l|}{ Symptom scales/items } \\
\hline Pain & -0.23 & NS \\
\hline Swallowing & $-0.33^{*}$ & \\
\hline Sense problems & $-0.73^{* * *}$ & \\
\hline Speech problems & -0.22 & NS \\
\hline Social eating & $-0.54^{* * *}$ & \\
\hline Social contact & $-0.39^{*}$ & \\
\hline Sexuality & $-0.52^{* * *}$ & \\
\hline Teeth & -0.28 & NS \\
\hline Opening mouth & -0.20 & NS \\
\hline Dry mouth & $-0.44^{* *}$ & \\
\hline Sticky saliva & $-0.57^{* * *}$ & \\
\hline Coughing & -0.17 & NS \\
\hline Feeling ill & $-0.56^{* * *}$ & \\
\hline
\end{tabular}

Correlation coefficients are positive for the functional scales because high scores on the Global QOL and on the functional scales indicate good status. Correlation coefficients are negative for the symptom scales because high scores on the Global QOL scale indicate good status, and high scores on the symptom scales/ items indicate poor status. Significance levels are indicated with ${ }^{*} \mathrm{p}<0.05,{ }^{* *} \mathrm{p}<0.01,{ }^{* * *} \mathrm{p}<0.001$, and NS $=$ nonsignificant.

\section{Correlations between Voice Handicap and HRQL}

Table 4 presents correlations between the total VHI score, as well as between the subscales of VHI, and the functional and symptom scales/items in the two EORTC questionnaires for the group of 43 patients. Total VHI was significantly correlated with all the functional scales in the EORTC QLQ-C30. The correlation between total
VHI and the Global QOL scale was also significant. Regarding the symptom scales and items in the EORTC QLQ-C30, significant correlations were found between total VHI and nausea/vomiting, pain, dyspnea, and financial difficulties.

Total VHI was significantly correlated with several of the head and neck symptoms in EORTC QLQ-H\&N35: pain, sense problems, speech problems, social eating, social contact, and sexuality. No significant correlations were found between total VHI and the questions on teeth, dry mouth and sticky saliva.

\section{Discussion}

\section{Voice Handicap Index}

In the present study the majority of patients perceived their VHI to be moderate, a result that is in agreement with previous studies of VHI in laryngectomees [7, 9, 11]. Mean total VHI for the 43 patients in the present study was $48.0 \pm(\mathrm{SD}) 21.2$, reflecting that $56 \%$ scored their VHI between 31 and 60 points. Almost a third of the patient group, $28 \%$, assessed their VHI to be severe, whereas $16 \%$ scored their handicap as low. In the studies by Schuster et al. [9] and Kazi et al. [11], the scores for the patient groups were more equally distributed over the three severity degrees of the VHI.

Regarding the subscales of VHI, scores in the present study were higher for the physical (mean 17.3) and functional (mean 18.6) subscales compared to the emotional (mean 12.1) subscale. The patients experienced voice production as strenuous, and the effort increased in noisy environments, with difficulties to make them heard. The interindividual difference was larger for the emotional subscale than for the other subscales. Within the patient group that assessed VHI as minimal or moderate, the scores for the emotional subscale were lower than for the patient group with high total VHI. In this group the subscale scores were more equally distributed among the three scales, which means that also the emotional subscale received a relatively high score (fig. 1).

According to a study by Van Gogh et al. [28], differences regarding VHI scores in group comparisons should be more than 15 points to be statistically and clinically relevant. In the present study no significant VHI differences were found between the age groups, or between groups that differed with respect to the postoperative period. This is most probably due to the limited number of participants in the study. As a consequence, the number of patients in each subgroup becomes small, and espe- 
Table 4. Correlations (Pitman's nonparametric permutation test) between VHI, total score and subscales, and between the scales and items of EORTC QLQ-C30 and QLQ-H\&N35 module

\begin{tabular}{|c|c|c|c|c|c|c|c|c|}
\hline \multirow[t]{2}{*}{ EORTC } & \multicolumn{2}{|c|}{ VHI total } & \multicolumn{2}{|c|}{ VHI functional } & \multicolumn{2}{|c|}{ VHI physical } & \multicolumn{2}{|c|}{ VHI emotional } \\
\hline & corr. & $\mathrm{p}$ & corr. & $\mathrm{p}$ & corr. & $\mathrm{p}$ & corr. & $\mathrm{p}$ \\
\hline \multicolumn{9}{|l|}{ QLQ-C30 } \\
\hline \multicolumn{9}{|l|}{ Functional scales } \\
\hline Global QOL & $-0.35^{*}$ & & -0.28 & NS & -0.27 & NS & $-0.35^{*}$ & \\
\hline Physical function & $-0.36^{*}$ & & -0.30 & NS & $-0.34^{*}$ & & $-0.33^{*}$ & \\
\hline Role function & $-0.37^{*}$ & & -0.27 & NS & $-0.30^{*}$ & & $-0.40^{* *}$ & \\
\hline Emotional function & $-0.50^{* * *}$ & & $-0.44^{* *}$ & & $-0.40^{* *}$ & & $-0.50^{* *}$ & \\
\hline Cognitive function & $-0.44^{* *}$ & & $-0.36^{*}$ & & $-0.30^{*}$ & & $-0.44^{* *}$ & \\
\hline Social function & $-0.56^{* * *}$ & & $-0.60^{* * *}$ & & -0.29 & NS & $-0.58^{* * *}$ & \\
\hline \multicolumn{9}{|l|}{ Symptom scales/items } \\
\hline Fatigue & 0.26 & NS & 0.25 & NS & 0.15 & NS & 0.29 & NS \\
\hline Nausea and vomiting & $0.49^{* *}$ & & $0.47^{* *}$ & & $0.31^{*}$ & & $0.52^{* *}$ & \\
\hline Pain & $0.31^{*}$ & & 0.29 & NS & 0.17 & NS & $0.34^{*}$ & \\
\hline Dyspnea & $0.37^{*}$ & & $0.36^{*}$ & & $0.34^{*}$ & & 0.29 & NS \\
\hline Insomnia & 0.11 & NS & 0.18 & NS & 0.04 & NS & 0.09 & NS \\
\hline Appetite loss & 0.06 & NS & -0.05 & NS & 0.12 & NS & 0.09 & NS \\
\hline Constipation & 0.21 & NS & 0.11 & NS & 0.19 & NS & 0.25 & NS \\
\hline Diarrhea & -0.09 & NS & -0.20 & NS & 0.02 & NS & -0.06 & NS \\
\hline Financial difficulties & $0.58^{* *}$ & & $0.45^{* *}$ & & $0.51^{* * *}$ & & $0.59^{* * *}$ & \\
\hline \multicolumn{9}{|l|}{ QLQ-H\&N35 } \\
\hline \multicolumn{9}{|l|}{ Symptom scales/items } \\
\hline Pain & $0.44^{* *}$ & & $0.36^{*}$ & & $0.31^{*}$ & & $0.49^{* *}$ & \\
\hline Swallowing & 0.10 & NS & 0.14 & NS & 0.05 & NS & 0.08 & NS \\
\hline Sense problems & $0.46^{* *}$ & & $0.39^{* *}$ & & $0.30^{*}$ & & $0.51^{* * *}$ & \\
\hline Speech problems & $0.63^{* * *}$ & & $0.64^{* * *}$ & & $0.53^{* * *}$ & & $0.52^{* * *}$ & \\
\hline Social eating & $0.36^{*}$ & & $0.36^{*}$ & & 0.24 & NS & $0.36^{*}$ & \\
\hline Social contact & $0.56^{* * *}$ & & $0.56^{* * *}$ & & 0.29 & NS & $0.62^{* * *}$ & \\
\hline Sexuality & $0.37^{*}$ & & $0.46^{* *}$ & & 0.25 & NS & 0.30 & NS \\
\hline Teeth & 0.20 & NS & 0.27 & NS & 0.01 & NS & 0.26 & NS \\
\hline Opening mouth & 0.27 & NS & 0.29 & NS & 0.08 & NS & $0.33^{*}$ & \\
\hline Dry mouth & 0.21 & NS & 0.13 & NS & 0.12 & NS & 0.29 & NS \\
\hline Sticky saliva & 0.29 & NS & 0.16 & NS & 0.29 & NS & $0.30^{*}$ & \\
\hline Coughing & 0.28 & NS & 0.23 & NS & 0.22 & NS & 0.29 & NS \\
\hline Feeling ill & 0.27 & NS & 0.26 & NS & 0.14 & NS & $0.31^{*}$ & \\
\hline
\end{tabular}

Correlation coefficients are negative for the functional scales of EORTC QLQ-C30, because high scores on the functional scales indicate good status, and high scores on the VHI indicate poor status. Correlation coefficients are positive for the symptom scales and items of EORTC QLQ-C30 and EORTC QLQ-H\&N35, because high scores on the symptom scales and items, as well as on the VHI, indicate poor status. Significance levels are indicated with ${ }^{*} \mathrm{p}<0.05,{ }^{* *} \mathrm{p}<0.01,{ }^{* * *} \mathrm{p}<0.001$, and NS = nonsignificant.

cially the groups with recently laryngectomized patients $(\mathrm{n}=9)$ and patients younger than 60 years $(\mathrm{n}=9)$. However, the higher total VHI (60.8) in the group with recently laryngectomized patients suggests that a voice handicap is perceived as more severe by newly laryngectomized compared to patients who had had a postoperative period of more than 1 year. Age also seemed to be important for the degree of voice handicap, with higher scores for the patients who were younger than 60 years, compared to the patients between 60 and 69 years, and 70 years and older. In the study of 54 patients by Kazi et al. [11], significant correlations were found between age and all three subscales of VHI, with higher scores in the younger age group. A prospective study of VHI for patients before and after laryngectomy would give further insight in coping strategies and acceptance of the changes in voice function in relation to age and length of postoperative period. 


\section{Health-Related Quality of Life}

The patients in the present study rated their Global QOL to be 66.8/100, where 100 reflects the highest possible Global QOL. Normative EORTC data from a Swedish population [29], age 60-69 years, with a diversity of physical problems, reported a 10-point higher Global QOL score (77.1), and normative data from the same age group without any physical problems reported a Global QOL score almost 20 points higher (85.2). Global QOL scores at this high level have been reported in previous studies of laryngectomees $[19,24,30]$. Op de Coul et al. [24] suggest that a score of 82.0 for Global QOL of the 79 laryngectomees in their study group might be due to selection bias, since the patients had good voices, were well rehabilitated, and were highly motivated to participate in a clinical trial of a special stoma device for TE speakers. A Swedish study reported Global QOL scores between 83 and 85 points [30]. These patients also participated in a treatment program (regarding olfaction) and were thus a selected group, as opposed to the patients in the present study who were recruited consecutively.

Problems with eating affected the level of Global QOL the most in the present study. Global QOL was significantly correlated to a number of parameters: dry mouth, sticky saliva, swallowing problems, problems eating together with family/friends, and sense problems (table 3, EORTC QLQ-H\&N35). The problem with scent perception, in combination with problems to swallow solid food, is likely to be the reason for problems with enjoying a meal and eating together with others.

Global QOL did not correlate significantly with speech problems, or with other aspects that may affect speech and respiration, such as problems with teeth, opening mouth/trismus, dyspnea, or coughing. The speech scale in the EORTC QLQ-H\&N35 consists of three questions. Two of the questions deal with problems concerning talking to other people, and problems with talking on the telephone. The third question concerns voice quality ('have you been hoarse?'). In our study, $65 \%$ of the patients answered 'not at all' to this question. Our findings agree with the results in the study by Op de Coul et al. [24], in which a high percentage of patients gave the same answer. These results suggest that the speech scale of EORTC QLQ H\&N-35 may not be sensitive enough to capture important aspects of the communicative impairment of laryngectomees.

Regarding breathing and its effect on the quality of life, only one question is asked about breathing problems, in the EORTC QLQ-C30: 'Were you short of breath?' (during the past week). In clinical experience, laryngec- tomees often complain about problems with breathing through the permanent tracheostoma, and with frequent coughing caused by the production of mucus from the lungs. It seems that the EORTC questionnaires do not cover the specific problems related to breathing and coughing in laryngectomees, nor is there any question about mucus production. This finding was also acknowledged by Op de Coul et al. [24].

\section{Relationships between VHI and HRQL}

Mohide et al. [31] asked 20 laryngectomees and 20 health care professionals to rank and rate important quality of life items for a laryngectomee. The laryngectomees ranked the 'physical consequences' and 'interference with social activities' as the most important items, while the health care professionals ranked 'impaired communication' and 'change in self-image' as the most important. Impaired communication truly interferes with social activities, something that was reflected in the high correlation between VHI and the EORTC questionnaires in our study (table 4). VHI was significantly correlated with all functional scales of EORTC QLQ-C30. The strong correlations between total VHI and the emotional and social functional scales show a connection between the patients' assessment of their voice function and their feelings of depression and anxiety and how their physical/medical treatment interferes with family and social life. Previous quality of life studies of laryngectomees in which SF-36 was used $[7,10]$ show opposite results regarding the correlations between VHI and general health. Stewart et al. [7] found no significant correlation between VHI and the SF-36's scale General Health in a group of 56 laryngectomees. In the study by Schuster et al. [10], significant correlations between VHI and General Health, as well as between VHI and the subscale Vitality, was found in a group of 20 male laryngectomees, although the interindividual ranges regarding both VHI and SF-36 were large. In the present study there was a significant correlation between VHI and the scoring of Global QOL $(r=-0.35, p<0.05)$. As seen in table 4, the correlation is based on the scoring of the VHI subscale 'emotional'.

The significant correlation between degree of VHI and the question about financial difficulties in EORTC QLQ-C30 reflects the scoring in the patient group aged 65 years or younger. These patients belong to the working population in our country, and are therefore likely to be more affected by different terms of insurance and economic conditions in comparison with older patients. At the time of the investigation many of the younger and re- 
cently operated patients had not yet been able to return to work.

The correlations between total VHI and the scales and items of EORTC QLQ-H\&N35 also reflected the difficulties with voice function, and how the perceived voice handicap affects social activities. This effect is also found in the significant correlation between VHI and the social contact scale in EORTC QLQ-H\&N35, in which the questions concern difficulties with interacting with family and friends, and with participation in public events. A dysfunctional voice, which results in a high VHI, is likely to cause social difficulties and result in limited social contacts.

\section{Conclusion}

The results from the present study suggest that many of the laryngectomized patients' problems are well described with the EORTC QLQ-C30 and QLQ-H\&N35. Especially useful is EORTC QLQ-H\&N35 regarding the symptoms from the head and neck area. However, these instruments do not fully capture the laryngectomees' specific breathing and speech problems. Based on the results in this study, we find VHI to be a valuable tool for assessment of the patients' voice function. Additional questions on breathing and coughing problems due to tracheal mucus production need to be included in any of the questionnaires used in this study, or by use of another questionnaire.

\section{Acknowledgments}

This study was supported by grants from The Foundation of the Swedish Association of Laryngectomees and from the Research and Education Committee at Karolinska University Hospital, Stockholm. We are indebted to Mikael Holtenman and NilsGunnar Pehrson, Statistiska Konsultgruppen, Göteborg, for help and advice in the statistical analysis, and to Eva B. Holmberg, Karolinska Institute, Stockholm, for valuable comments on the manuscript.

\section{References}

1 Singer MI, Blom ED: An endoscopic technique for restoration of voice after laryngectomy. Ann Otol Rhinol Laryngol 1980;89: 529-533.

2 Hilgers FJ, Schouwenburg PF: A new low-resistance, self-retaining prosthesis (Provox) for voice rehabilitation after total laryngectomy. Laryngoscope 1990;100:1202-1207.

3 Hilgers FJM, Aaronson NK, Ackerstaff AH, Schouwenburg PF, van Zandwikj N: The influence of a heat and moisture exchanger (HME) on the respiratory symptoms after total laryngectomy. Clin Otolaryngol 1991; $16: 152-156$

4 Van As CJ, Hilgers FJM, Koopmans-van Beinum FJ, Ackerstaff AH: The influence of stoma occlusion on aspects of alaryngeal speech. Acta Otolaryngol 1998;118:732-738.

5 Jacobson B, Johnson A, Grywalski C, Silbergleit A, Jacobson G, Benninger M, Newman C: The Voice Handicap Index (VHI): development and validation. Am J Speech Lang Pathol 1997;6:66-70.

-6 Verdonck-de Leeuw IM, Kuik DJ, De Bodt M, Guimaraes I, Holmberg EB, Nawka T, Rosen CA, Schindler A, Whurr R, Woisard V: Validation of the Voice Handicap Index by assessing equivalence of European translations. Folia Phoniatr Logop 2008;60:173178 .
Stewart MG, Chen AY, Stach CB: Outcomes analysis of voice and quality of life in patients with laryngeal cancer. Arch Otolaryngol 1998;124:143-148.

8 Moerman M, Martens JP, Dejonckere P: Application of the Voice Handicap Index in 45 patients with substitution voicing after total laryngectomy. Eur Arch Otorhinolaryngol 2004;261:423-428.

-9 Schuster M, Lohscheller J, Hoppe U, Kummer P, Eysholdt U, Rosanowski F: Voice handicap of laryngectomees with tracheoesophageal speech. Folia Phoniatr Logop 2004;56:62-67.

10 Schuster M, Toy H, Lohscheller J, Eysholdt U, Rosanowski F: Lebensqualität und Stimmbeeinträchtigung Laryngektomierter mit Stimmventilprothesen. Laryngorhinootologie 2005;84:101-107.

11 Kazi R, De Cordova J, Singh A, Venkitaraman R, Nutting CM, Clarke P, Rhys-Evans P, Harrington KJ: Voice-related quality of life in laryngectomees: assessment using the VHI and V-RQOL symptom scales. J Voice 2007;21:728-734.

12 Ware JE, Sherbourne CD: The MOS 36-item short-form health survey (SF-36) 1. Conceptual framework and item selection. Med Care 1992;30:473-483.
13 Armstrong E, Isman K, Dooley P, Brine D, Riley N, Dentice R, King S, Khanbhai F: An investigation into the quality of life of individuals after laryngectomy. Head Neck 2001; 23:16-24.

14 Schuster M, Lohscheller J, Kummer P, Hoppe U, Eysholdt U, Rosanowski F: Quality of life in laryngectomees after prosthetic voice restoration. Folia Phoniatr Logop 2003;55:211219.

15 de Graeff A, de Leeuw RJ, Ros WJG, Hordijk GJ, Blijham GH, Winnubst JAM: Long-term quality of life of patients with head and neck cancer. Laryngoscope 2000;110:98-106.

16 Hammerlid E, Bjordal K, Ahlner-Elmqvist M, Boysen M, Evensen JF, Biörklund A, Jannert M, Kaasa S, Sullivan M, Westin T: A prospective study of quality of life in head and neck cancer patients. Part I: At diagnosis. Laryngoscope 2001;111:669-680.

17 Bjordal K, Ahlner-Elmqvist M, Hammerlid E, Boysen M, Evensen JF, Biörklund A, Jannert M, Westin T, Kaasa S: A prospective study of quality of life in head and neck cancer patients. Part II: Longitudinal data. Laryngoscope 2001;111:1440-1452.

18 Hammerlid E, Silander E, Hörnestam L, Sullivan M: Health-related quality of life three years after diagnosis of head and neck cancer - a longitudinal study. Head Neck 2001; 23:113-125. 
-19 Nordgren M, Abenstein H, Jannert M, Boysen $M$, Ahlner-Elmqvist M, Silander E, Bjordal K, Hammerlid E: Health-related quality of life five years after diagnosis of laryngeal carcinoma. Int J Radiat Oncol Biol Phys 2003;56:1333-1343.

20 Braz DSA, Ribas MM, Dedivitis RA, Nishimoto IN, Brandao Barres AP: Quality of life and depression in patients undergoing total and partial laryngectomy. Clinics 2005;60: 135-142.

-21 Aaronson NK, Ahmedzai S, Bergman B, Bullinger M, Cull A, Duez NJ, Filiberti A, Flechtner H, Fleishman SB, de Haes JC: The European Organization for Research and Treatment of Cancer QLQ-C30: a quality-oflife instrument for use in international trials in oncology. J Natl Cancer Inst 1993;85:365376.

-22 Bjordal K, Hammerlid E, Ahlner-Elmqvist M, de Graeff A, Boysen M, Evensen JF, Biörklund A, de Leeuw JR, Fayers PM, Jannert M, Westin T, Kaasa S: Quality of life in head and neck cancer patients: validation of the European Organization for Research and Treatment of Cancer Quality of Life Questionnaire-H\&N35. J Clin Oncol 1999;17: 1008-1019.
23 Kaasa S, Bjordal K, Aaronson N, Moum T, Wist E, Hagen S, Kvikstad A: The EORTC core quality of life questionnaire (QLQC30): validity and reliability when analysed with patients treated with palliative radiotherapy. Eur J Cancer 1995;31A:2260-2263.

24 Op de Coul BMR, Ackerstaff AH, van As CJ, van den Hoogen FJA, Meeuwis CA, Manni JJ, Hilgers FJM: Quality of life assessment in laryngectomized individuals: do we need additions to standard questionnaires in specific clinical research projects? Clin Otolaryngol 2005;30:169-175.

25 Ohlsson AC: Voice Handicap Index in Swedish - validation and reliability. 3rd Pan European Voice Conference, Stockholm, 2001.

26 Reference to www.voicecenter.upmc.com/ VoiceHandicapIndex.htm.
27 Fayers PM, Aaronson NK, Bjordal K, Groenvold M, Curran D, Bottomley A: The EORTC QLQ-C30 Scoring Manual, ed 3. Brussels, European Organization for Research and Treatment of Cancer, 2001.

28 Van Gogh CDL, Mahieu HF, Kuik DJ, Rinkel RNPM, Langendijk JA, Verdonck-de Leeuw IM: Voice in early glottic cancer compared to benign voice pathology. Eur Arch Otorhinolaryngol 2007;264:1033-1038

29 Michelson H, Bolund C, Nilsson B, Brandberg Y: Health-related quality of life measured by the EORTC QLQ-C30: reference values from a large sample of the Swedish population. Acta Oncol 2000;39:477-484.

30 Risberg-Berlin B, Ylitalo Möller R, Finizia C: Effectiveness of olfactory rehabilitation with the nasal airflow-inducing maneuver after total laryngectomy. Arch Otolaryngol Head Neck Surg 2007;133:650-654.

>31 Mohide EA, Archibald SD, Tew M, Young JE, Haines T: Postlaryngectomy quality-of-life dimensions identified by patients and health care professionals. Am J Surg 1992;164:619622 . 